\title{
Animabox: Proposta de um OA Orientado ao Ensino de Fundamentos de Estratégias Empresariais na Educação Superior Márcio Marins ${ }^{1}$, Evandro Manara Miletto ${ }^{2}$
}

\author{
${ }^{1}$ Departamento de Pós-graduação do Centro Universitário Uniftec/FGV \\ Caxias do Sul - RS - Brasil \\ ${ }^{2}$ Instituto Federal de Educação, Ciência de Tecnologia do Rio Grande do Sul (IFRS) \\ Campus Porto Alegre - Porto Alegre - RS - Brasil \\ marciomarinseftec.com.br, evandro.milettodpoa.ifrs.edu.br
}

\begin{abstract}
This paper describes the potential contributions of Animabox, as an learning object, as a supporting tool for the teaching and learning processes about specifcs fundaments into the Business Strategies subjetc, in higher education. To achieve this goal, this research was based on a comparative experiment wihch allowed to infere the students reached the objectives proposed into the referred subject, building their own knowledge with autonomy and in a decentralized way mediated by the tool here presented.
\end{abstract}

Resumo. O presente artigo avalia as potenciais contribuições do Animabox, enquanto objeto de aprendizagem, como suporte no processo de ensino e aprendizagem de fundamentos específicos da disciplina de Estratégias Empresariais, no ensino superior. Para tal, esta pesquisa se apoiou em um experimento comparativo que permitiu constatar que os acadêmicos cumpriram com os objetivos propostos pela disciplina, construindo seu próprio conhecimento de forma autônoma e descentralizada.

\section{Introdução}

Na perspectiva de Behar et al. (2009), os materiais didaticos digitais, na forma de objetos e aprendizagem (OA), vêm enriquecendo o espaço pedagógico ao remeter o aluno a um novo tipo de aprendizagem apoiada pelas tecnologias, possibilitando que conceitos e conteúdos sejam apresentados de forma mais dinâmica e interativa. Marins e Miletto (2017) explicam que, do ponto de vista pedagógico, o aporte das tecnologias é capaz de transferir para o aluno o papel de agente ativo no processo de aprendizagem, possibilitando a ele a construção de um novo conhecimento; guiando-o à obtenção de percepções totalmente novas e, até, inesperadas.

Na visão de Kensky (2007), o que faz dos OAs relevantes instrumentos de apoio à educação vai além do particionamento dos conteúdos em formatos digitais como, por exemplo, áudio, vídeo, animações, desenhos, atividades e textos. Para a autora, a disposição destes objetos em repositórios virtuais permite que os OAs possam ser empregados para o ensino de um mesmo assunto em diferentes áreas do conhecimento, representando, assim, um importante recurso no desenvolvimento de novas estratégias didáticas nas mais diferentes disciplinas.

Neste sentido, busca-se, com o presente trabalho, avaliar de que forma a dinâmica proposta por um OA pode contribuir com o processo de ensino e aprendizagem dos fundamentos das análises organizacional e macroambiental na disciplina de Estratégias 
VII Congresso Brasileiro de Informática na Educação (CBIE 2018)

Anais do XXIX Simpósio Brasileiro de Informática na Educação (SBIE 2018)

Empresariais, na esfera da educação superior. Para responder à pergunta de pesquisa, foi desenvolvido o Animabox, um objeto de aprendizagem cuja premissa é explorar tais princípios teóricos e que são a base da Matriz SWOT - ferramenta que, de acordo com Oliveira (2014), tem como propóstito identificar os quatro pilares que fazem parte do ambiente estratégico de qualquer organização: as forças $(\mathrm{S})$ e fraquezas $(\mathrm{W})$, que são elementos que compõe a análise organizacional; e, as oportunidades $(\mathrm{O})$ e ameaças $(\mathrm{T})$, princípios macroambientais (Figura 1).

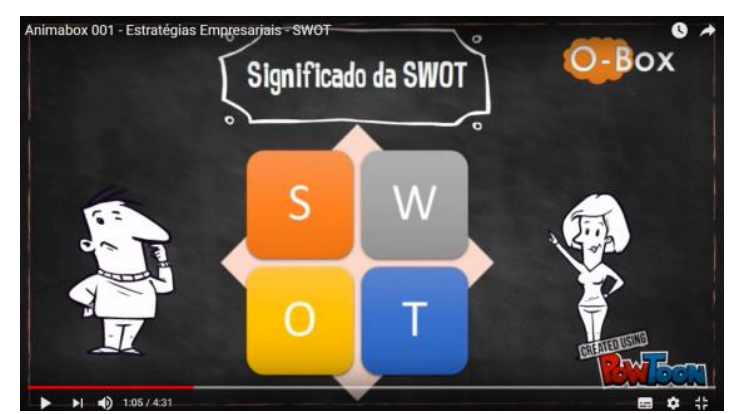

Figura 1. Imagem do Animabox 001 sobre a Matriz SWOT.

Hospedado na plataforma YouTube ${ }^{1}$, o Animabox foi desenvolvido reunindo quatro dos formatos digitais elencados por Kensky (2007), sendo eles: a combinação entre áudio, vídeo e animação, empregada para a sua construção; e, um questionário com oito questões para verificação de aprendizagem, formulado no software Hot Potatoes ${ }^{2}$.

O artigo está estruturado da seguinte forma: na seção 2, apresenta-se a metodologia que guiou a condução do estudo; na seção 3, apresentam-se os resultados do experimento prático envolvendo a aplicação do Animabox em sala de aula; e, na seção 4 são colocadas as considerações finais sobre o presente estudo.

\section{Metodologia}

O presente artigo envolve uma pesquisa experimental, de caráter exploratório-descritivo, com pesquisa mista e com levantamento de dados através de questionário e observação direta. Este estudo foi realizado com duas turmas dos cursos de graduação em negócios matriculados na disciplina de Estratégias Empresariais, do primeiro semestre de 2017, matéria esta oferecida pela instituição que aqui será chamada de Universidade 1, entidade particular de ensino superior localizada na cidade de Caxias do Sul.

Tratando-se de um estudo comparativo, o objetivo central do experimento foi o de analisar as contribuições do Animabox para com o desempenho dos alunos em uma atividade que já estava prevista no conteúdo programático da disciplina de Estrategias Empresariais e que consistia em um questionário, composto por oito questões, onde os acadêmicos precisavam relacionar pequenos cases com os pilares da SWOT (Figura 2).

A amostra empregada para este estudo foi composta por 34 acadêmicos, sendo 22 da primeira turma e os demais 12 da segunda. Todos foram convidados a participar voluntariamente do experimento, sendo este dividido em quatro etapas. A primeira consistiu em uma entrevista individual para identificação de conhecimentos prévios sobre os fundamentos teóricos explorados pelo Animabox. A segunda abrangeu a interação dos participantes com o $\mathrm{OA}$ em um ambiente acadêmico informatizado e com acesso à

\footnotetext{
${ }^{1}$ Disponível em: https://www.youtube.com/channel/UC64PUPIxDFS808bxIHOivSw

${ }^{2}$ Disponível em: http://meuobox.wixsite.com/obox/quiz-animabox-002
} 
VII Congresso Brasileiro de Informática na Educação (CBIE 2018)

Anais do XXIX Simpósio Brasileiro de Informática na Educação (SBIE 2018)

internet. Nesta etapa, aos alunos foram dados 15 minutos para que interagissem com o Animabox, podendo fazer uso do OA mais de uma vez se assim o desejassem.

Para otimizar a apuração dos resultados da aprendizagem, o questionário aplicado na terceira etapa foi operacionalizado na plataforma Moodle. Na última etapa, os alunos fizeram a validação do OA através de um forlmulário do Google, onde eles responderam dois questionamentos quantitativos: um a respeito da influência direta do Animabox no desempenho obtido na atividade avaliativa e outro sobre o formato preferido por eles para a transmissão e assimilação de conhecimentos acadêmicos. Ainda foi disponibilizado um espaço opcional onde eles puderam destacar suas contribuições qualitativas.

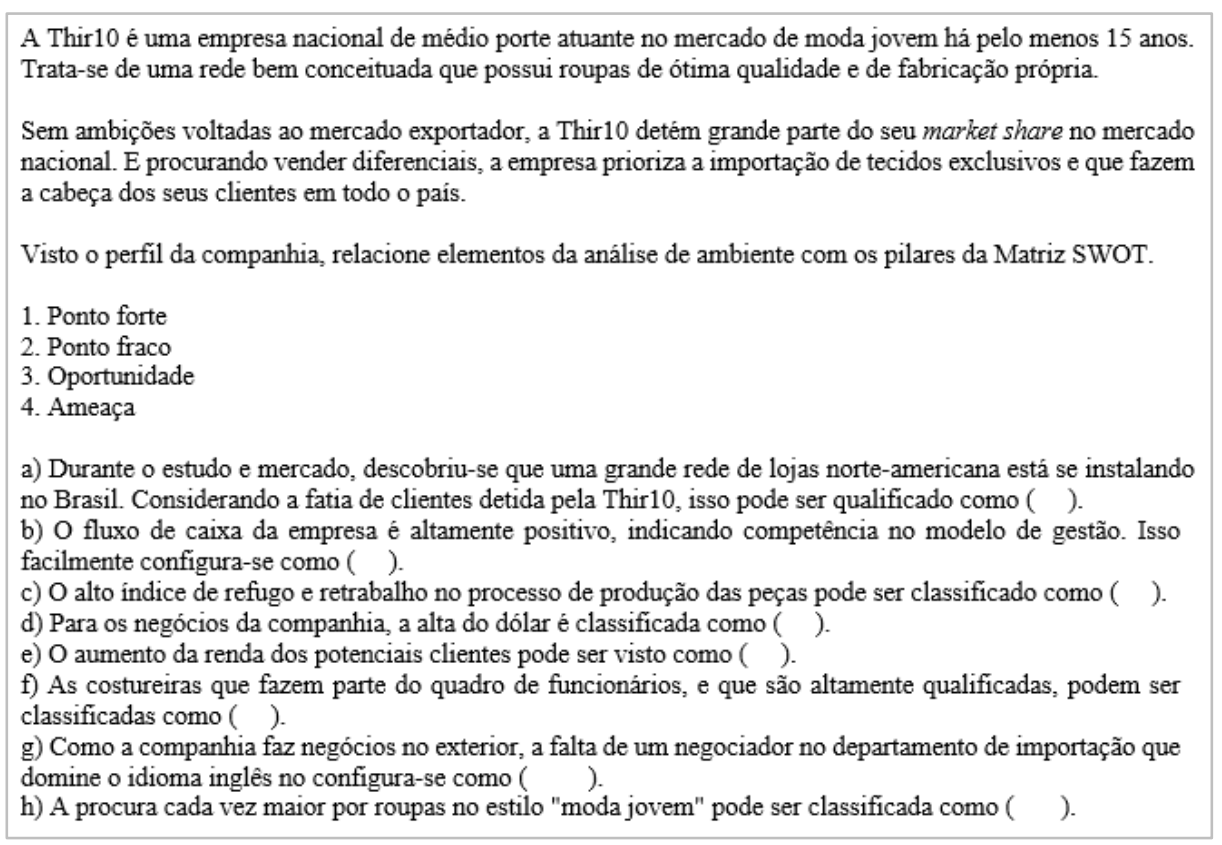

Figura 2. Questionário sobre análise situacional, baseado na Matriz SWOT.

Como parâmetro comparativo foram utilizados os dados do desempenho médio dos alunos da mesma disciplina, todavia da turma de 2016/2, formada por 33 acadêmicos. Ainda que o aproveitamento histórico em semestres anteriores tenha sido similar neste mesmo questionário, a escolha pela turma de 2016/2 deu-se pelo fato de que esta foi a última a trabalhar com os fundamentos explorados pelo Animabox no formato tradicional, onde os conceitos eram apresentados de forma expositiva. Neste caso, não apenas fica garantido o comparativo com uma amostra que não teve interação com o OA objeto deste estudo, como, também, assegurado um trabalho sustentado em dados mais recentes.

Embora o questionário seja aplicado como um critério parcial para aprovação na cadeira de Estratégias Empresariais, é importante salientar que o instrumento em questão foi aqui empregado em caráter não obrigatório, sem penalidades para os alunos que optassem não participar da atividade. Isso porque fez-se o entendimento de que a obrigatoriedade da avaliação poderia comprometer a mensuração da livre adesão dos estudantes ao experimento; tal como o fato de o pesquisador principal ser o professor da citada disciplina poderia comprometer os resultados da validação do OA.

Evidencia-se, portanto, que a ideia central foi criar clima mais propício à expontaniedade e engajamento ao projeto que possibilitasse aos pesquisadores a obtenção de percepções autênticas com relação ao uso do Animabox enquanto tecnologia de apoio na construção do conhecimento e na solidificação dos conceitos por ele abordados. 
VII Congresso Brasileiro de Informática na Educação (CBIE 2018)

Anais do XXIX Simpósio Brasileiro de Informática na Educação (SBIE 2018)

\section{Resultados obtidos}

Por se tratar de atividades com participação facultativa, viu-se como muito positiva a adesão de $100 \%$ dos alunos matriculados na matéria. Potencialmente, a não obrigatoriedade e um perfil de alunos com maior afinidade pelo aprendizado através das tecnologias (vide Figura 4b) podem ter gerado maior estímulo de cooperação com a presente pesquisa.

Como forma de garantir a eficiência nos resultados do experimento, através de uma entrevista individual, buscou-se identificar se os participantes tinham conhecimento prévio sobre os fundamentos teóricos explorados pelo Animabox. Cinco acadêmicos afirmaram ter tido um contato muito superficial com as referidas teorias em outra matéria que abordava o uso de ferramentas gerenciais. Segundo eles, houve uma breve menção à Matriz SWOT, porém sem qualquer aprofundamemento.

Depois disso, os alunos foram conduzidos ao laboratório de informática e, antes de interagirem com o OA, lhes foi explanada a proposta do experimento. Após findado o tempo de interação com o OA, em seguida os acadêmicos responderem o questionário, fazendo com que se constatasse um crescimento significativo no desempenho dos mesmos quando comparados ao grupo de estudantes que não fez uso do Animabox. O aproveitamento médio em ambas as turmas de 2017/1 chegou muito próximo de $99 \%$, contra 58,71\% da turma de 2016/2 (Figura 3).

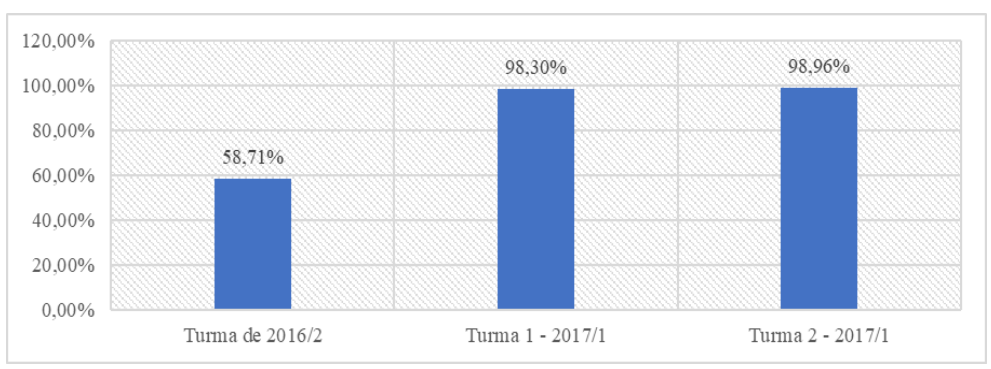

Figura 3. Avaliação da aprendizagem usando o Animabox.

$\mathrm{Na}$ visão dos alunos, como mostra a Figura 4(a), o uso do Animabox influenciou diretamente no nível de assertividade alcançado - o que é totalmente ratificado por $71 \%$ deles. Nesta perspectiva, uma justificativa para este percentual pode estar relacionada com o alto grau de afinidade dos alunos com o processo de aprendizagem através de diferentes tipos de mídias digitais, sendo que os formatos de áudio, vídeo e outras mídias eletrônicas estão entre os preferidos por $85 \%$ dos participantes do experimento - vide Figura 4(b).

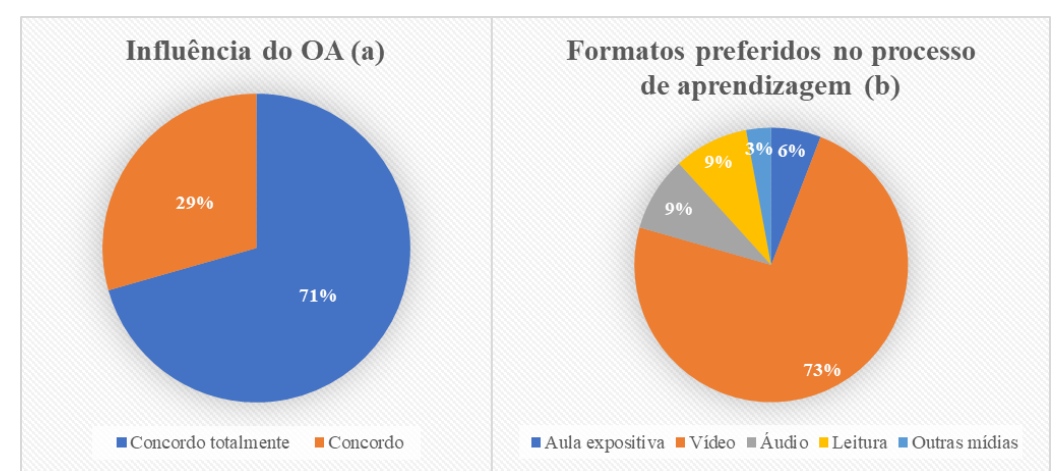

Figura 4. Validação dos acadêmicos (a) quando à influência direta do Animabox nos resultados alcançados e (b) sobre os formatos preferidos pelos alunos no processo de aprendizagem. 
VII Congresso Brasileiro de Informática na Educação (CBIE 2018)

Anais do XXIX Simpósio Brasileiro de Informática na Educação (SBIE 2018)

$\mathrm{Na}$ parte final da validação, sete contribuições discursivas avaliaram positivamente o Animabox. Os cinco alunos que inicialmente apontaram ter algum conhecimento sobre o assunto destacaram que, somente após interagirem com o OA, conseguiram ter maior elucidação sobre as análises organizacional e macroambiental. $\mathrm{O}$ outro respondente afirmou que a maneira com que foram estruturados os assuntos no Animabox tornou o processo de aprendizagem mais interessante e prazeroso. $\mathrm{O}$ último aluno a contribuir qualitativamente afirmou que assistir ao conteúdo através de um vídeo curto e objetivo fez o tema explorado ficar mais atrativo e menos complexo. Ele ainda acrescentou que o Animabox o ajudou reforçar sua aprendizagem, mesmo após o experimento, já que o conteúdo estava disponível e acessível a qualquer hora.

\section{Considerações finais}

Ao longo do presente artigo, notou-se que a dinâmica favorecida pelo Animabox acabou se mostrando oportuna ao viabilizar, aos acadêmicos do ensino superior, uma percepção maior e descentralizada sobre os fundamentos teóricos do ambiente organizacional e macroambiental e sua contextualização em problemáticas amplamente discutidas em sala de aula - o que é importante tanto para a assimilação de tais princípios na disciplina de Estratégias Empresariais quanto na vida prática destes futuros profissionais.

A partir do quadro evidenciado no presente estudo, foi possível não apenas reconhecer a pertinência do Animabox no que tange a esfera proposta nesta pesquisa. Constatou-se, também, que os objetos de aprendizagem, quando adotados de forma apropriada, surgem como valiosas ferramentas de mediação do conhecimento, possibilitando ao aluno a construção do próprio aprendizado com facínio e autonomia.

Não se pode deixar de mencionar, no entanto, que a familiaridade dos estudantes com as tecnologias no processo de aprendizagem oportunizou a construção de uma atmosfera favorável à tal pertinência, o que proporcionou uma dinâmica de aprendizagem centrada nos alunos e a implementação de um recurso didático compativel com o perfil destes acadêmicos que, cada vez mais, ratificam sua afinidade com o mundo digital.

Tem-se o entendimento de que a velocidade com que os alunos evouem digitalmente potencializa a relevância de um projeto com este direcionamento em outras áreas. Dessa forma, propõe-se a realização de um novo estudo comparativo a partir do desenvolvimento de um novo Animabox que contemple três conceitos muito presentes no ensino da administração: logística, logística integrada e logística empresarial.

\section{Referências}

1. Behar, P. A.; Macedo, A. L.; Souza, A. P. F. C; Bernardi, M. (2009). Objetos de Aprendizagem para Educação à Distância. In: Behar, P. A. (org). Modelos Pedagógicos em Educação à Distância, Porto Alegre, Artmed, Cap. 3.

2. Kensky, V. M. (2007). Educação e Tecnologias: o novo ritmo da informação. Campinas, Papirus, $3^{\circ}$ Edição.

3. Marins, M.; Miletto E. M. (2017). Box Plus: um protótipo para suporte ao design thinking na educação empreendedora. In: IV Congresso Brasileiro de Informática na Educação, Recife, Anais do WTME, p. 495-504.

4. Oliveira, D. P. R. (2014). Planejamento Estratégico: conceito, metodologias e práticas. São Paulo, Atlas, $32^{\circ}$ Edição. 